\title{
COMBATES POR EL LIBRO: INCONCLUSA DIALÉCTICA DEL MODELO DIGITAL
}

\author{
Combats for the book: A play on words with the \\ digital model
}

José-Antonio Cordón-García

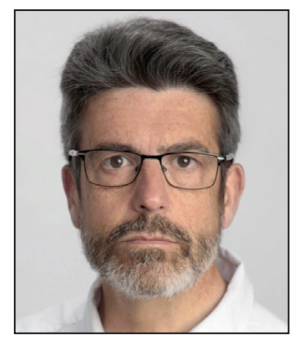

José-Antonio Cordón-García es catedrático de Bibliografía y Fuentes de Información en la Universidad de Salamanca (USAL). Sus líneas de investigación se centran en el estudio de la industria editorial y las fuentes de información, áreas en las que ha publicado varias monografías y artículos. Es director del grupo de investigación reconocido (GIR) E-lectra; director del Master oficial en patrimonio textual y humanidades digitales de la USAL. Recibió un premio nacional de investigación en edición y sociedad del conocimiento. http://orcid.org/0000-0002-8569-9417

Universidad de Salamanca, Facultad de Traducción y Documentación Francisco de Vitoria, 6-16. 37008 Salamanca, España jcordon@usal.es

\section{Resumen}

El libro electrónico es una realidad en el sector editorial con cifras de crecimiento que muestran su progresivo afianzamiento en los mercados de todo el mundo. Su recorrido en los últimos 15 años, muestra las paradojas y contradicciones que toda nueva tecnología ha de abordar en su proceso de implantación. También las múltiples resistencias de una industria editorial todavía con fuertes cautelas hacia los nuevos modelos de negocio, imputables principalmente a los efectos de la piratería y de la fragilidad de un sistema en plena transición. Al tiempo que esto ocurre por el lado de la producción, por el de la recepción, la lectura digital muestra cifras contundentes de una progresión indudable, aunque conformando un modelo en el que el libro va perdiendo su espacio de centralidad, y en el que lo impreso sigue manteniendo cuotas de atracción fuertemente competitivas con los nuevos sistemas.

\section{Palabras clave}

Libros electrónicos; Lectura digital; Edición electrónica; Investigación sobre lectura; Sector editorial.

\section{Abstract}

In the publishing sector, electronic book growth figures have shown progressive consolidation in markets around the world. The electronic book evolution in the last 15 years shows the paradoxes and contradictions that every new technology has to address in its implementation process. In addition, the editorial industry is resistant to new business models due to the possibilities of piracy and the fragility of a system in full transition. And, although digital reading is on the upswing and shows undoubted progression, the print book remains central to publishing and continues to maintain strongly competitive odds with the new systems.

\section{Keywords}

Electronic books; Digital reading; Electronic publishing; Reading research; Publishing sector.

Cordón-García, José-Antonio (2018). “Combates por el libro: inconclusa dialéctica del modelo digital”. El profesional de la información, v. 27, n. 3, pp. 467-481.

https://doi.org/10.3145/epi.2018.may.02

\section{Introducción}

Recientemente, el director ejecutivo de la editorial Hachette Livre, Arnaud Nourry, calificaba al libro electrónico como un "producto estúpido". La declaración, que provocó cierto escándalo, se difundió rápidamente por las redes sociales, obligando a su autor a matizar el alcance de sus palabras, que constituyen en su conjunto un buen diagnóstico del momento actual de gran parte de la industria editorial di- gital. Apelaba a la falta de creatividad, a la inexistencia de experiencias reales para los lectores, a la masiva tendencia al mimetismo impreso en la mayoría de los libros electrónicos publicados. Decía:

“El libro electrónico es un producto estúpido porque, en última instancia, es exactamente lo mismo que el impreso, pero en formato digital. No hay creatividad, ni enriquecimiento, ni experiencia digital real". 
Han transcurrido poco más de 10 años desde que los libros electrónicos irrumpieran en el mercado con vocación de permanencia. Antes de la aparición de la tinta electrónica, y de la creación de empresas donde la integración vertical de contenidos, dispositivos y venta constituían sus señas de identidad (Amazon, Apple, Google, etc.) se habían producido multitud de ensayos que jugaban con la atractiva idea de incrementar la accesibilidad de la producción cultural mundial, de en cierto modo satisfacer la aspiración de gran parte de las políticas de democratización cultural que se habían empezado a implementar en Europa y Estados Unidos a partir de la década de los 50 del siglo XX. Esto es, conseguir un acceso universal a la cultura, equilibrando las condiciones de producción, mediación y difusión de la misma. La aparición de internet por un lado y los avances tecnológicos por otro, propiciaban un contexto en el que este anhelo podía sustanciarse de una manera razonable. Iniciativas como el Proyecto Gutenberg (auspiciado por el malogrado Michel Hart desde 1971) o Google Prints, luego Google Books, discurrían por esas vías. Los libros electrónicos se enmarcaban en esta lógica, que subyace en toda la historia de la información y la documentación a lo largo de los siglos, involucrándose en una deriva en la que la apertura y la flexibilidad se conciliaban con la visibilidad y la accesibilidad, al menos en propuestas y pretensiones.

Las expectativas generadas por la aparición de nuevos formatos, nuevos dispositivos y nuevas formas de lectura fue tal que a nadie extrañó que, ya en el año 2011, se vaticinara en la Feria del Libro de Fráncfort la defunción de los libros en papel para fechas tan tempranas como el año 2018, amparándose en las experiencias de la prensa, las revistas científicas o las obras de referencia, cuya migración digital era un hecho consumado. El debate impreso-digital estaba servido, y numerosas plumas lo han ido alimentando mediante reflexiones, investigaciones, y también ocurrencias, que han puesto de manifiesto que algo aparentemente inocuo o marginal, como el lugar del libro en la cultura, en realidad constituía y constituye un aspecto sustancial de los debates contemporáneos, que la simbología de éste es mucho más potente de lo que las estadísticas de consumo sugieren, y que todavía quedan muchas batallas por librar en ese terreno.

La simbología del libro es mucho más potente de lo que las estadísticas de consumo sugieren: todavía quedan muchas batallas por librar en el tema impreso-digital

A defensores y detractores del libro impreso y de los libros electrónicos, se les podía aplicar la sentencia atribuida a Atanasio, obispo alejandrino del siglo IV que decía:

"Si el mundo va contra la verdad, entonces Atanasio va contra el mundo".

$Y$ es que las posturas a veces son tan irreconciliables que se puede detectar cierto dogmatismo en las mismas, en los términos de irracionalidad que el concepto implica.
Si el libro impreso llevó hasta sus últimas consecuencias la optimización de los procesos lógico-formales de representación física, conformando un utensilio casi perfecto para navegar en el proceloso mundo de lo escrito, el libro electrónico representa la culminación de una forma de racionalismo postmoderno en el que el pensamiento deviene líquido, no sólo por la versatilidad de la interpretación, sino también por la de los dispositivos de producción. La dicotomía herramienta-máquina sirve para explicar las disyuntivas de ambos entornos, en los que la usabilidad implícita en la primera, evidenciada en la propia forma por una funcionalidad explícita, se oculta en la segunda a través de sistemas complejos que requieren de habilidades y competencias de desvelamiento e interpretación más especializados.

\section{El tiempo se ha convertido en el terreno donde se libra la competición}

El concepto de affordance sirve para explicar muchos de los debates, apegos y desapegos que se producen en la sociedad contemporánea respecto a los contenidos digitales. EI término fue acuñado por primera vez por James J. Gibson en 1977, describiéndolo cómo

"Todas las posibilidades que materialmente ofrece un objeto para reconocer cómo usarlo".

Lo que introduce es una relación epistémica entre el agente y su medio, que surge cuando el agente detecta una información específica que le permite modular su acción. Lo que está implícito en el libro impreso como instrumento es la posibilidad de articular un ciclo continuo de percepción-acción. Se trata de un movimiento estable que ha permanecido casi invariable durante siglos y que ha situado a todo lector en una zona de confort en la que las funciones implícitas en el objeto sugerían usos diversos pero controlados. Con las máquinas de leer, con los dispositivos, con los contenidos digitales, esta zona de confort ha desaparecido:

- en primer lugar, por representar una "terra incognita" para la mayoría de la población;

- en segundo lugar, por estar sometida al principio de la aceleración y del cambio permanente, en el que la velocidad es la medida de la eficiencia;

- en tercer lugar, por alejarse de la simplicidad de la herramienta para expandirse en funcionalidades múltiples; y

- en cuarto lugar, por situarse en un contexto en el que el valor ha derivado de lo tangible a lo intangible.

Si la escasez es la medida del precio, y del aprecio, el tiempo se ha convertido en el terreno donde se libra la competición. Pero la naturaleza de éste sigue siendo "analógica", insoslayable y constreñida a usos excluyentes, por lo que la pugna en su conquista se beneficia de la tradición y de la renuncia a las incertidumbres atribuidas a los nuevos medios. Las industrias culturales se mueven en un contexto en el que la repetición, la satisfacción y el consenso constituyen el bucle que sostiene su pervivencia y reproducción, un bucle en el que los eventos traumáticos, en términos de cambios de paradigma, prueban sus fortalezas y capacidad de resiliencia.

El discernimiento para evaluar la innovación es un valor 
cultural dependiente en gran medida de la capacidad de adaptación de todos los actores involucrados en el fenómeno de que se trate. En el caso del libro se trata de un sistema complejo en el que las disfunciones entre la creación, la producción y el consumo han estado siempre presentes bajo la tiranía de una economía de prototipos que distorsiona el funcionamiento normal del mercado. Pero si estas disfunciones, en términos de oferta, demanda, y prácticas culturales asociadas a la misma, eran ya poderosas en el territorio de lo impreso, se han agudizado en el digital, provocando precarios equilibrios que se van dilucidando a través de propuestas que cabalgan entre la innovación y la obsolescencia programada. Decía Thoreau que nuestros inventos no son más que medios mejorados para un fin que no mejora (Alonso-Burgos, 2017), y esto es aplicable a muchas de las innovaciones desarrolladas en el entorno de la lectura digital, en tanto que los medios no han conseguido incrementar los niveles de lectura, auténtico agujero negro de la cultura contemporánea. Al fin y al cabo, la lectura es una forma de procesar información que remite a universos reales o de ficción, en función de las condiciones a priori del lector. Sabemos que alguien lee, no cuánto de lo que lee es procesado efectivamente. Los relatos sobre la lectura son rayas sobre el agua, decir de lo inefable, pretensión de apresar lo inasible. La cantidad de información que resta después de un libro es inapreciable, como es inapreciable el proceso reticular que cada unidad de significado genera en el cerebro. Cada término se agarra a todos los núcleos semánticos con que puede guardar relación, reforzando algunos, borrando otros o creando nuevos. ¿Cómo medir ese movimiento interno que bulle y crece, decrece y se reacomoda permanentemente?

\section{Los nuevos medios no han conseguido incrementar los niveles de lectura}

Nos encontramos pues en un momento fascinante en el que por primera vez gracias a la emergencia de un nuevo modelo, hemos podido vislumbrar, después de 500 años la potencia metafórica y cultural del sistema impreso, cuyos ejes basculan muy lentamente en otra dirección todavía sin determinar, pues siendo lo digital el magma en el que se mueve, aún no aparece el "diseño inteligente" que le sirva de hoja de ruta fundacional. En sus estudios, la historiadora estadounidense Eisenstein (1994) sostenía que, por lo menos en los cincuenta años que siguieron a la introducción de la imprenta no existieron evidencias significativas de cambio cultural. No fue sino hasta un siglo después de Gutenberg cuando empezaron a verse los contornos de los primeros retratos de un nuevo mundo. Si la velocidad es el signo de los tiempos, la provisionalidad es la condición de los acontecimientos, y en ella nos movemos para cualquier reflexión que se haga sobre lo digital.

Lucien Febvre en una de sus obras de referencia, Combates por la Historia, reflejaba las tensiones, las luchas, las fuerzas en pugna cuando aparecen nuevos modelos de análisis historiográfico. También en el sector del libro se están librando permanentes combates, en términos simbólicos y reales, entre realidades contrapuestas o que tienden a presentarse como tales. Se trata de un discurso dialéctico en el que las razones pivotan entre la tesis y la antítesis y en menor medida en la síntesis, sobre un principio de equilibrio e intercambio de valor que actúa sobre oposiciones establecidas: impreso-digital, abierto-cerrado, propiedad-acceso, herramienta-maquina, etc., que constituyen el fundamento de nuestro actual desorden especulativo.

En los cincuenta años que siguieron a la introducción de la imprenta no hubo evidencias significativas de cambio cultural

\section{El combate de las cifras: la producción y la recepción}

\subsection{La producción}

Las cifras, que interesaban únicamente a los responsables de políticas culturales, a empresarios y especialistas en la evolución de la economía y las empresas, desde la aparición de los libros electrónicos comenzaron a trascender esos círculos restringidos para aparecer en todo tipo de medios, sujetas a interpretaciones múltiples y contradictorias. Y es que este es un terreno en el que la batalla ideológica y simbólica se hace más virulenta por cuanto constituye el reflejo objetivable de la consolidación de los nuevos modelos, o de la pervivencia de los antiguos.

En este sentido el interrogante se sitúa sobre la penetración o no de la producción digital, desde el punto de la oferta (evolución del mercado) y desde el punto de la demanda (consumo y lectura digital). El problema de este tipo de análisis es concretar dónde se ubica el horizonte de expectativas y en qué términos se mide éste, pues no es lo mismo valorar la evolución de un mercado en el corto plazo, sobre todo cuando éste se alimenta de la innovación, que en el largo plazo, para comprobar el grado de consolidación del mismo. Ni comparar hábitos y comportamientos fuertemente asentados, con sistemas emergentes en igualdad de condiciones. Pero haciendo en cierta medida abstracción de estas circunstancias, las cifras empiezan a ser significativas respecto a la irrupción de lo digital en el mercado del libro en el que, por otra parte, los procesos tanto de creación como de producción y comunicación están completamente digitalizados.

Las cifras de la irrupción de lo digital en el mercado del libro empiezan a ser significativas, aunque son dispares y distantes según la fuente utilizada

Las cifras del mercado de libros digitales en la actualidad son dispares y distantes según la fuente utilizada. En España se producen diversos informes y estudios que arrojan datos contradictorios pues unos confirmarían la idea del estancamiento, mientras que otros alimentarían el argumento del 


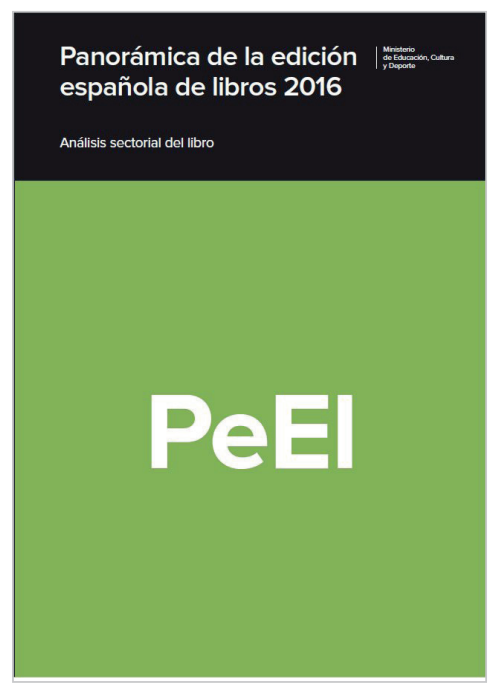

https://sede.educacion.gob.es/publiventa/ panoramica-de-la-edicion-de-libros-2016/ edicion $/ 21061 \mathrm{C}$

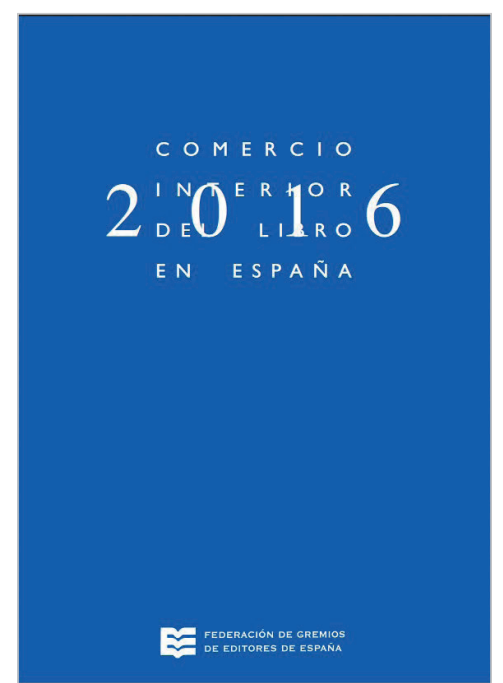

http://federacioneditores.org/img/ documentos/Comercio_Interior_16.pdf

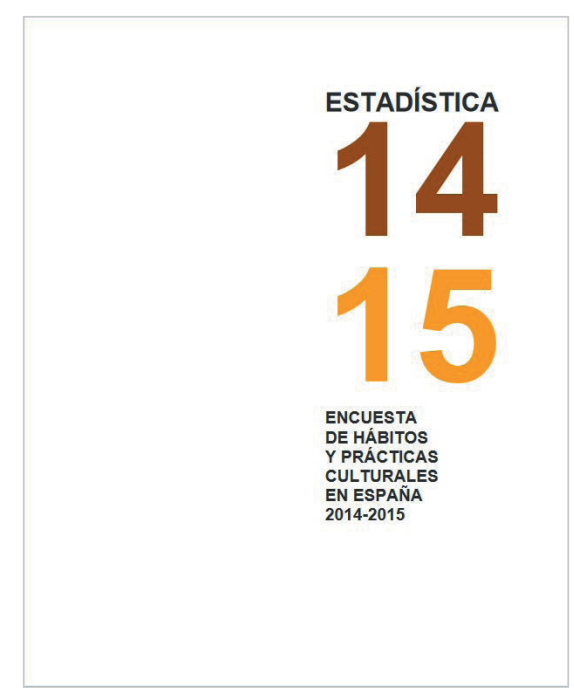

https://www.mecd.gob.es/servicios-al-ciudadano/ estadisticas/cultura/mc/ehc/2014-2015/ presentacion.html crecimiento. Los siguientes informes constituyen las fuentes a partir de las cuales comenzar a obtener datos relativos sobre el contexto en el que se mueven el libro electrónico y la lectura digital:

- Panorámica de la edición española de libros (Ministerio de Educación, Cultura y Deporte);

- Comercio interior del libro (Federación de Gremios de Editores);

- El comercio exterior del libro (Fedecali);

- Encuesta de hábitos y prácticas culturales (MECD);

- Encuesta de hábitos de lectura y compra de libros (Federación de Gremios de Editores), vuelta a realizar después de desaparecer en 2012;

- informes de Dosdoce y BookWire.

En España la producción de títulos digitales se aproxima ya a los 25.000 anuales, lo que constituye casi un 30\% del total de la producción. En estos momentos un cuarto de las editoriales españolas está produciendo edición digital. Las cifras de facturación global abarcan un abanico que oscila entre el 5,1\% del total (Panorámica de la Edición Española de Libros, 2017) o el $11 \%$ que arroja el estudio desarrollado por Dosdoce y BookWire (2018). Se trata de datos en la línea de los países de nuestro entorno como Alemania, con un mercado de libros electrónicos en torno al 4,6\% (Boersenverein; GfK, 2018), Francia, con un 8,5\% (Observatoire, 2018), Italia y otros países en torno al 5\% (European book statistics, 2017) y bastante alejados de los de Estados Unidos o Reino Unido, con un mercado digital más maduro que comprende el $25 \%$ de la producción aproximadamente (Wischenbar, 2017). Si contemplamos la evolución desde un punto de vista diacrónico se observa una progresión constante en todos los proce- sos relacionados con lo digital. Las series de datos contempladas desde una década de antigüedad, años en los que los dispositivos de tinta electrónica empiezan a expandirse, aunque su aparición es anterior, arrojan resultados claramente positivos, más si tenemos en cuenta el poco tiempo transcurrido. 10-15 años para un mercado de bienes culturales constituye un período de tiempo muy reducido. Sin embargo los resultados en términos de eficiencia son bastante razonables, al menos lo suficiente como para que podamos afirmar sin lugar a dudas que la tendencia a la digitalización de contenidos que se había verificado en revistas y obras de referencia también se consolida en los libros. El error en todos estos años ha consistido en analizar el proceso como un fenómeno de desplazamiento, y no de acompañamiento, como una maniobra de sustitución, y no de convergencia. Desde ese punto de vista la interpretación sería evidentemente negativa pues la velocidad de la implantación digital no responde a los ritmos que se vaticinaban en sus estadios iniciales, cuando los entusiastas de los nuevos formatos alimentaron previsiones claramente distópicas.

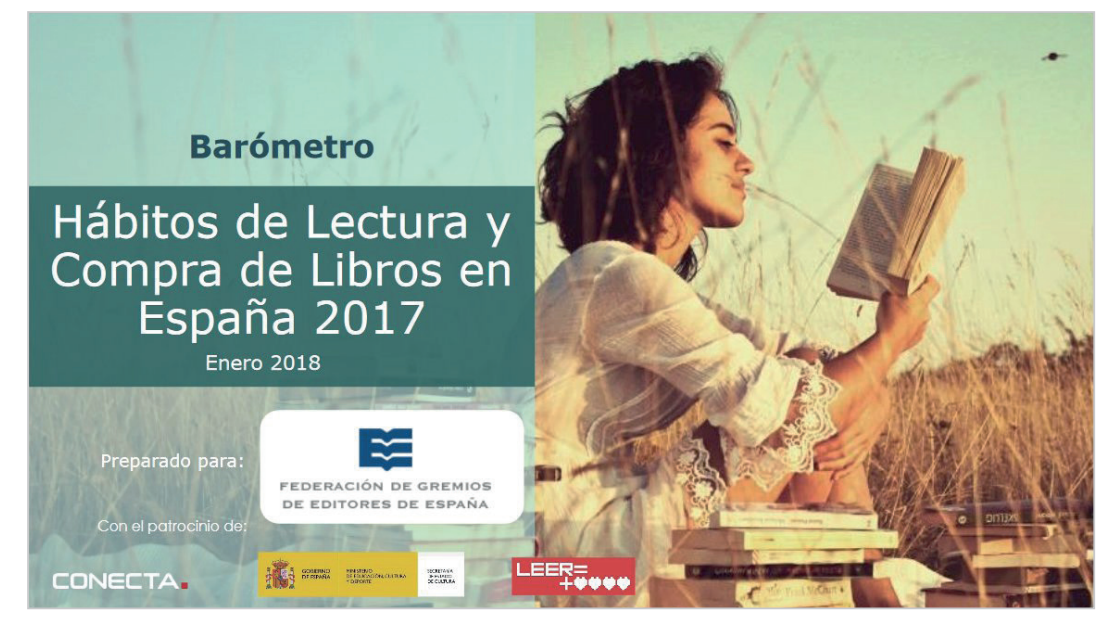

http://federacioneditores.org/img/documentos/HabitosLecturaCompraLibros2017.pdf 


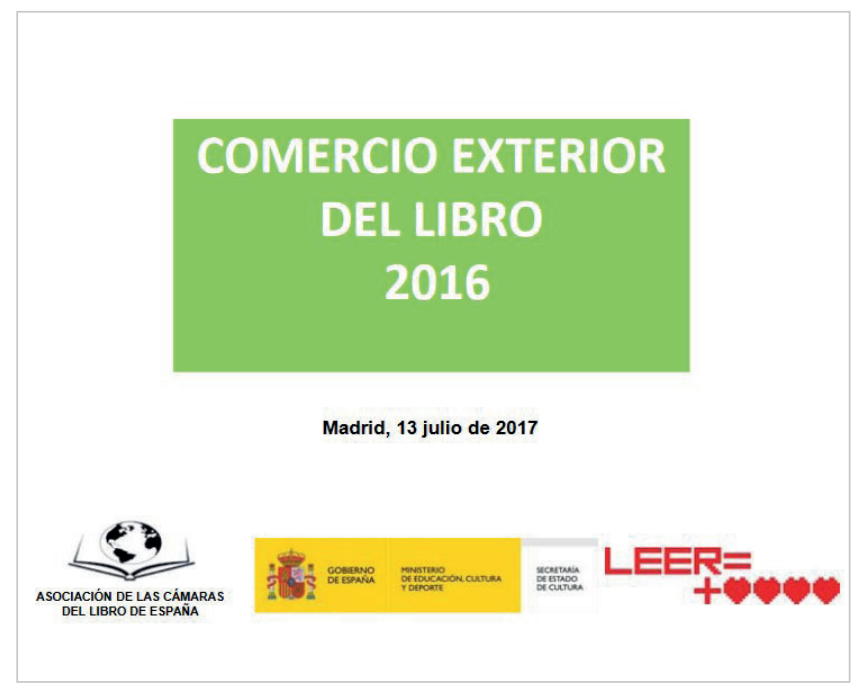

https://goo.gl/GCjpch

\section{$\|$ IIU}

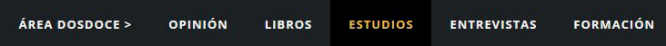

\section{ESTUDIOS}

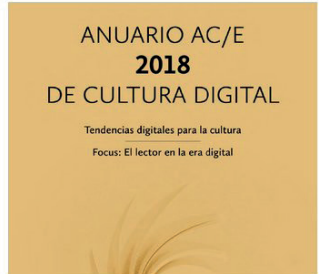

Anuario AC/E de Cultura Digital 2018

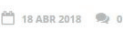

Son ya cinco las ediciones del Anuario ACIE

Cultur Disital llevadas a cabo dor Accion Cut

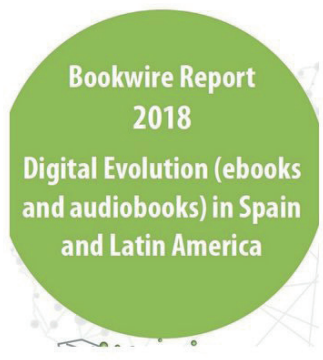

Strong growth in ebooks sales in 2017 in Spain and Latin America http://www.dosdoce.com/category/estudios-3

conocibles y amigables. En el caso del libro electrónico, la producción además está mediatizada por los riesgos implícitos en las descargas ilegales que en muchos casos suponen un freno el afán innovador de parte de la industria. Según el último informe MUSO (2018) los sitios de descarga ilegal recibieron 300 mil millones de visitas en 2017, lo que representa un aumento del 1,6\% en comparación con el año anterior.

Estados Unidos, Rusia y la India, acaparan casi la mitad de todo el tráfico de la misma. Lo paradójico es la irrelevancia de los libros en el cómputo global de las descargas. Según este informe las retransmisiones y programas de televisión recibieron 106.900 millones de visitas, la música, 73.900 millones, las películas, 53.200, y los ebooks poco menos de 50 millones.

Los sitios de descarga ilegal recibieron 300 mil millones de visitas en 2017, lo que representa un aumento del $1,6 \%$

Según el informe de la Intellectual Property Office del Reino Unido para el año 2017, el $17 \%$ de los libros electrónicos leídos online están pirateados, es decir, alrededor de 4 millones de libros (Intellectual Property Office, 2017). Por otra parte, la firma holandesa GfK, estipula que en el año 2017 sólo el $10 \%$ de todos los libros electrónicos alemanes fueron pagados, siendo la mayoría de los libros digitales pirateados. Según esta misma firma, un lector de libros electrónicos posee de media 117 libros electrónicos en los Países Bajos, de los que sólo 11 habrían sido comprados de manera legal, y los restantes pirateados. En Rusia, el 92\% de los lectores de libros electrónicos los habrían obtenido de manera irregular. En España, los datos existentes los aporta la Coalición de Creadores e Industrias de Contenidos que publica anualmente el Observatorio de la piratería y hábitos de consumo de contenidos digitales. En su última edición, Observatorio de la piratería 2017, se informa que el $24 \%$ de los internautas accede a libros en formato digital de forma ilegal, un $2 \%$ más que el año anterior, mismo porcentaje de incremento 
de que los que lo hacen de forma legal.

http://lacoalicion.es

http://lacoalicion.es/observatorio-de-la-pirateria/observatoriode-la-pirateria-2017

De cualquier manera la cuestión no es cuántos acceden de forma ilegal, sino qué representa esto para la industria, pues la descarga de una obra pirata no equivale a una compra fallida. En este sentido el Observatorio desarrolla una teoría acerca del lucro cesante: lo que la industria deja de percibir por el efecto de estas actuaciones. El lugar relativo del lucro cesante respecto a su repercusión en la industria se estipula sobre su representación en un escenario de no piratería. En el caso de los libros esto representaría un incremento del $9 \%$ en el valor global de la industria, que en el caso de la música sería el $264 \%$, en el cine el $61 \%$, en los videojuegos el $30 \%$, en las series el $128 \%$, o en el fútbol el $26 \%$.

\section{La cuestión no es cuántos acceden de} forma ilegal, sino qué representa esto para la industria, pues la descarga de una obra pirata no equivale a una compra fallida

Una de las razones fundamentales aducidas por aquellos que recurren a las descargas ilegales son los inconvenientes planteados por el DRM (digital rights management), en tanto que limita el uso que se puede hacer de los libros que se han comprado legalmente, restringiendo las opciones razonables de utilización, como poder copiar, imprimir, prestar, etc. Algunos editores han respondido a esta situación mediante la adopción de sistemas más suaves como la marca de agua digital (digital watermarks) asumida por Pottermore, o por HarperCollins, entre muchos otros. La investigación sobre el impacto de las técnicas de mitigación de la piratería, como la marca de agua, es prácticamente inexistente. Reimers (2016) mostró en un estudio sobre la aplicación de algunas medidas sobre la búsqueda de copias no autorizadas en la Red que se podían incrementar en un $14 \%$ las ventas de libros electrónicos con ciertos sistemas antipiratería vigentes.

Una de las razones aducidas por los que hacen descargas ilegales son los inconvenientes planteados por el DRM

De cualquier modo las previsiones sobre la evolución del mercado son optimistas, y así lo atestigua el estudio $E$-books market in Europe 2018-2022 (2018), en el que se pronostica que el mercado de libros electrónicos en Europa crecerá a una tasa compuesta anual de $4,58 \%$ durante los próximos cinco años, con una intervención significativa de algunos de los principales actores del sector editorial actual, decididamente volcados hacia lo digital: Amazon, Georg Von Holtzbrinck, Hachette Livre, HarperCollins Publishers, McGrawHill Education, Pearson, Penguin Random House, Rakuten Kobo y Simon \& Schuster.

\subsection{La recepción}

Si los datos referentes a la oferta muestran un panorama en vías de consolidación, con una oferta digital regular y en crecimiento, los relativos a lectura muestran un escenario en el que las paradojas y los equilibrios muestran tendencias aun sin consolidar.

Los estudios y encuestas sobre libros y lectura son bastante contradictorios y por lo tanto susceptibles de interpretaciones múltiples. En el informe sobre el sector del libro y la lectura en España de 2017 (Observatorio del libro y la lectura, 2017), se indica que la lectura es la segunda actividad cultural más practicada por los españoles, después de la audición de música, con unos porcentajes que alcanzan al $62 \%$ de la población. Sin embargo, en todas las encuestas sobre prácticas de lectura comprobamos que más de la mitad de la población no ha leído nunca un libro y que los lectores frecuentes constituyen una minoría. Lo mismo ocurre con la lectura digital, que ha experimentado una progresión evidente en los últimos años, pero dentro de un contexto de contención privativo de esta actividad. Los informes coordinados por José-Antonio Millán $(2002,2008,2017)$ sobre la lectura en España son contundentes. En sus sucesivas ediciones muestran que la lectura progresa globalmente, pero la centrada en los libros cuenta con un núcleo de resistencia fuerte hacia los mismos, en torno al $40 \%$ de la población que, además, en un alto porcentaje argumenta que no lee porque no le interesa (Encuesta de hábitos y prácticas culturales, 2016).

\section{Las previsiones sobre la evolución del mercado son optimistas}

A pesar de esto, si tomamos como referencia el panorama de unos años atrás, podemos comprobar como tanto la producción de libros electrónicos como de lectores en digital ha ido en aumento. Este incremento ha estado auspiciado, sin duda, por la ruptura con el campo editorial tradicional, así como con las prácticas de lectura convencional, expandiendo hacia escenarios nuevos las actividades vinculadas con ambos elementos. Nuevos formatos, nuevos géneros, nuevos comportamientos frente al texto, han favorecido la generación de una cultura que, sin romper todavía el cordón umbilical con el entorno impreso, se va adentrando en territorios cada vez más alejados de éste. Nos encontramos ante escenarios con un alto grado de experimentalidad, en el que los tiempos de supervivencia de las propuestas son efímeros y a veces imperceptibles, pero en el que se van consolidando tendencias exclusivas del nuevo entorno, con movimientos que beben de la tradición, pero desde una perspectiva completamente renovada, como ocurre con la autopublicación, los audiolibros o los sistemas de recomendación (Cordón-García, 2016a; 2018; Cordón-García; Gómez-Díaz; García-Rodríguez; 2016b)

El estatus de la lectura en el contexto digital, sigue trufado de luces y de sombras, propias de la indefinición de todo sistema que se va consolidando, pero sin un perfil definitivo. En este sentido se habla de lo postdigital como elemento caracterizador del momento actual (Paganelli, 2017). Aunque el término 
no sea novedoso, de hecho, Negroponte ya lo había utilizado en un artículo de 1998 (Negroponte, 1998) y posteriormente Davies (2009); Wetzig (2012); Taffel (2015); Cramer (2015); o Colletti (2016) entre otros, no deja de resultar llamativo el uso que se hace de él. El prefijo post hace alusión a lo que hay "después de", pero no tanto en el sentido temporal sino estructural. No se trata de una mera sucesión, sino de una superación. Se habla de postmodernidad, de posthumanismo, de postbiología, o más recientemente de postverdad, para designar realidades alternativas constituidas sobre las ruinas de lo precedente. En cierto modo lo post es una superación de lo anterior, pero también una negación de su pervivencia. No es este el caso, pues en la bibliografía de referencia se habla del paso de lo digital a lo postdigital en el sentido de la existencia de una segunda ola, en la que el acento no se pone tanto sobre la tecnología y los dispositivos, sino sobre las prácticas y el consumo, en tanto que las primeras gozan ya de ciertas dosis de madurez y control. Es más, la bibliografía científica apunta hacia la emergencia de síntomas de fatiga por uso o abuso de los nuevos medios tecnológicos, e incluso a cierta regresión a formatos tradicionales en sectores de población aparente más propicios, por educación y hábitos, al uso de los dispositivos.

\section{La bibliografía científica apunta hacia la emergencia de síntomas de fatiga por uso o abuso de los nuevos medios tec- nológicos}

Un estudio publicado en Publishers Weekly (Milliot, 2016) correlaciona la disminución de las ventas y la lectura digital con el cansancio provocado por los formatos electrónicos. Además de factores de carácter contextual, se apunta como explicación al síndrome de "fatiga digital" que tiene que ver con la usabilidad de los dispositivos, con el cansancio atribuible a la conectividad forzada, y con el uso excesivo de pantallas. En una encuesta realizada por el Codex Group, en Estados Unidos, el 25\% de los encuestados compradores de libros electrónicos confiesa la necesidad de distanciarse de sus dispositivos móviles, y un $19 \%$ de los entrevistados confiesa que leen menos libros electrónicos en la actualidad que cuando comenzaron a emplear esos formatos, manifestando una preferencia por la vuelta a los formatos impresos. http://www.codexgroup.net

Lo curioso es que esta voluntad de retorno es inversamente proporcional con la edad, es decir que son los más jóvenes, los que pasan más tiempo entre pantallas, los que manifestarían una mayor inclinación a retomar las prácticas de lectura impresa.

Otro estudio desarrollado por investigadores de tres universidades australianas (Merga; Roni, 2017), muestra como los niños que acceden regularmente a dispositivos electrónicos (sin diferenciar entre tabletas, teléfonos inteligentes y dispositivos de tinta electrónica) apenas los usan para leer, aunque sean lectores regulares en papel, que prefieren al digital. Un dato interesante del estudio es que se da igualmente una relación inversamente proporcional entre uso de los dispositivos y niveles de lectura. Zielinski (2015), advierte sobre el peligro de la sobreexposición al entorno digital, del que sin duda una consecuencia puede ser ésta, pero esto forma parte del relato de los hechos a los que aludíamos al principio, y no de los hechos, que admiten explicaciones menos lineales.

\section{Los estudios y encuestas sobre libros y lectura son bastante contradictorios}

Es cierto que la fatiga digital como teoría puede cautivar por su simplicidad, pero la perspectiva desde la que se aborda es excesivamente corta como para articular una tendencia verdaderamente consistente, amparada además por unas estadísticas de escaso recorrido todavía. Sin embargo, constituye un excelente ejemplo para analizar cómo funciona, en el nivel más ideologizado, el análisis de las tendencias relativas a los contenidos digitales. En algunos de los estudios que llegan a conclusiones similares no se tiene en cuenta ni los tipos de obras que se leen ni el tipo de dispositivo en el que efectúa la lectura, más allá de identificar que se trata de contenidos digitales. La literatura científica muestra cómo los niveles de compresión lectora están directamente relacionados con el tipo de pantalla que se emplea, sus dimensiones y prestaciones. Un estudio de la University of A/berta en 2010, y replicado en 2016 (Meyer, 2016), demuestra que los niveles de comprensión y la velocidad de lectura de contenidos complejos están determinados por el tipo de pantalla empleado para ello. Pero también con el tipo de aplicaciones que se emplean. Caroline Myrberg (2017) se preguntaba por qué hay tantos estudiantes a los que no les gusta leer libros electrónicos y prefieren el papel. La respuesta, como apunta la autora, tiene que ver con factores implícitos en el propio formato, la usabilidad de los dispositivos, las expectativas del lector y otras circunstancias. Pero la respuesta radica también en supuestos vinculados con las culturas imperantes, con las pugnas por la conquista de los espacios de creación y de interpretación, por la inserción de prácticas que revelan los graves contrastes de mentalidades discursivas existentes en el relato de lo literario.

Según el informe The monitor report 2018 de Childwise, que encuestó a 2.000 jóvenes en el Reino Unido, los niños de 9 a 16 años pasan media hora leyendo materiales impresos como libros, cómics y revistas, todos los días, y media hora leyendo contenido online como blogs, fan fiction y revistas online. Sin embargo, la forma en que los niños leen cambia a medida que llegan a la adolescencia. Los que tienen entre 9 y 12 años leen sin conexión el doble de tiempo que online, mientras que los de 13 a 16 años pasan el doble de tiempo leyendo online, según este informe.

http://www.childwise.co.uk/monitor.html

Pero lo impreso reviste un peso muy significativo en las prácticas de lectura. En el estudio publicado por Library journal (2018), sobre la experiencia de lectura de libros electrónicos entre los estudiantes, los resultados son extremadamente significativos, pues los contenidos digitales adquieren cierta relevancia en la investigación, pero aparecen muy distanciados cuando se trata de la lectura por placer o de las lecturas recomendadas. 
Cuando se trata de la lectura por placer casi tres cuartas partes de los encuestados (74\%) dijo preferir los libros impresos, en comparación con el $12 \%$ que prefiere los libros electrónicos (14\% no expresó ninguna preferencia de formato). Del mismo modo, el 68\% manifestó su inclinación por los libros impresos para la lectura narrativa, en comparación con el $23 \%$ que prefiere los libros electrónicos. En general, los estudiantes ven los libros impresos como más fáciles de leer y los libros electrónicos más fáciles de obtener. Tres cuartas partes de los encuestados (75\%) está de acuerdo o muy de acuerdo con la afirmación

"Soy más capaz de leer libros impresos que libros electrónicos".

Además, una mayoría (81\%) estuvo de acuerdo o muy de acuerdo en que

"Si un libro impreso no está disponible, un libro electrónico es una buena alternativa".

Son interesantes las respuestas sobre las desventajas en el uso y lectura de libros digitales pues apuntan a problemas todavía no resueltos por parte de editores y agregadores de contenidos. El principal inconveniente que señalan es el DRM en tanto que establece restricciones a la impresión de ciertos contenidos, a la descarga de capítulos o a la posibilidad de leer obras sin conexión, lo que dificulta considerablemente la práctica académica. En este sentido más de la mitad (56\%) de los encuestados se manifestó frustrado con las restricciones de DRM. Ordenadores portátiles y móviles son, con diferencia, los dispositivos más populares para acceder a los contenidos digitales. Una abrumadora mayoría de estudiantes (96\%) señaló el ordenador portátil como principal vía de acceso al contenido, seguido de teléfonos inteligentes (48\%), ordenadores de escritorio (22\%) o tabletas $(12 \%)$. Es curioso comprobar la preferencia por el pdf como formato de lectura (90\%), frente a un $19 \%$ que emplean epub o un $16 \%$ mobi.

Cuando se trata de la lectura por placer, el 74\% dijo preferir los libros impresos

Un aspecto interesante de estos estudios es la desmitificación que entre ellos tiene la lectura como una actividad que otorga prestigio o reconocimiento. Está claro que cuando confiesan que nunca leen, lo hacen porque implícitamente asocian la lectura a la lectura de libros, pero su intensa actividad en redes implica formas muy variadas de lectura digital, con un fuerte componente de lectura social. Ésta ha sido objeto de numerosos estudios y análisis, y si existe una caracterización inequívoca del comportamiento lector en la sociedad digital es precisamente el afán de comunicarse, de intercambiar opiniones, de compartir lecturas, en definitiva de socializar su experiencia. El éxito de redes como Whattpad, Goodreads, Librarything, y muchas otras constituyen una evidencia del empuje de un comportamiento socializador respecto a las prácticas culturales en general y a la lectura en particular. Esta tendencia no es algo nuevo: de hecho el síndrome de la comunicabilidad está implícito en los hábitos lectores desde hace siglos, como puede rastrearse en las numerosas memorias, correspondencias y reflexio- nes biográficas y autobiográficas existentes, en las que el proselitismo bibliográfico constituye uno de sus elementos fundamentales. Lo novedoso en la actualidad radica en las posibilidades que la tecnología ha desencadenado, transformado en universal o global una experiencia anteriormente limitada por las restricciones de lo impreso. En este sentido lo social se ha extendido en varios frentes estrechamente interconectados:

- redes sociales especializadas;

- redes sociales generales con sitios específicos de colaboración y recomendación;

- blogs especializados en formas particulares de literatura que actúan como recomendadores implícitos;

- aplicaciones de lectura social;

- funciones de socialización en aplicaciones de lectura general;

- canales de recomendación generales y especializados (booktubers); y

plataformas comerciales con sistemas de recomendación.

Si existe una caracterización inequívoca del comportamiento lector en la sociedad digital es el afán de comunicarse

La lectura se ha convertido en social, como se puede percibir contemplando el contingente de tweets, posts o publicaciones que generan los cientos de hashtags relacionados con libros y autores. Para los integrantes de la cadena del libro esto implica que la prescripción y la influencia se ha transferido en parte a los lectores, y que de una prescripción descendente (críticos, medios, librerías, bibliotecas) se ha producido el desplazamiento a una ascendente, en la que los lectores son cada vez más sensibles a los comentarios, notas y discusiones que aparecen en estas plataformas sociales. Blogueros, youtubers y otros actores de este micro marketing digital se han convertido en referentes para cientos de miles de usuarios que siguen con fidelidad sus recomendaciones, más efectivas desde el punto de vista de la difusión de una obra que la tradicional publicidad, dada la posibilidad de alcanzar a comunidades de intereses más especializados. Gracias a ello se establecen relaciones basadas en la confianza, la autenticidad y la proyección, generando por lo tanto niveles de compromiso reforzados por los algoritmos de Facebook, Instagram o YouTube. Las comunidades de lectores, los fans fictions, los grupos de clubs de lectura digital crecen, y desarrollan prácticas sólo posibles gracias a las prestaciones tanto de las aplicaciones de lectura como de las redes vinculadas a las mismas. En este sentido es interesante comprobar la disociación cognitiva y práctica que se produce entre blogueros y booktubers, como ejemplo de movimientos novedosos en materia de recomendación lectora, respecto a los nuevos entornos. Gemma Lluch (2017) aborda el estudio del comportamiento lector de jóvenes y adolescentes a partir del análisis de los blogs y canales de vídeo elaborados por un grupo de éstos en la Red. Resulta significativo comprobar cómo las generaciones más jóvenes de lectores aprovechan la Red para proyectar sus inquietudes, gustos literarios y creaciones, pero su comportamiento digital no se extiende a la lectura, que 
prefieren, en su mayoría en papel. Esta circunstancia, refrendada por numerosas investigaciones (Merga; Roni, 2017; Two Sides, 2017; Perbal, 2017; Singer; Alexander, 2017; Myrberg, 2017); Baron, 2016; Bruneau, 2016; Kaufman; Flanagan, 2016) y por los informes que se publican en casi todos los países, da fe de los diferentes ritmos que lo digital reviste en sus procesos de asimilación. En Australia, por ejemplo, el interés por la lectura de libros ha disminuido de un $41 \%$ a un $32 \%$ en el período 2011-2017, una disminución atribuible según el estudio Reading the reader (2017), al fuerte incremento de la lectura en redes sociales. Lo que podríamos denominar como una práctica propia de las generaciones más alfabetizadas digitalmente no ha encontrado aún su anclaje en estos sectores en lo que se refiere a las formas de lectura más canónicas que, además, cada vez aparecen más contaminadas por los modelos de lectura digital. Un estudio llevado a cabo entre va-

rios miles de niños y adolescentes ingleses (Topping, 2017), mostraba cómo en una gran cantidad de casos los lectores saltan páginas e incluso capítulos enteros en sus lecturas.

La situación de la lectura digital en todo el mundo se nutre de numerosas paradojas, como algunas de las apuntadas más arriba y, dentro de la inevitable progresión de una práctica cada vez más extensiva, si se la extrae del estrecho marco de la lectura de libros, los altibajos y los contrastes seguirán pautando su caracterización durante los próximos años. Por poner el ejemplo de la situación en España, el Informe Hábitos de lectura y compra de libros (FGEE, 2018), afortunadamente recuperado por la Federación de Gremios de Editores de España después de varios años de silencio, aporta interesantísimos datos sobre este contexto inestable del que hablamos. Un aspecto significativo es que los lectores en soporte digital se han incrementado del $47,8 \%$ al $76,3 \%$ del 2010 al 2017, una subida soportada por los lectores frecuentes, esto es los que leen al menos una vez a la semana. Pero lo más interesante es comprobar cómo se descompone la lectura digital según los tipos de lectura. Los porcentajes más elevados se corresponden con la lectura de redes sociales $(56,9 \%)$, blogs y webs $(49,5 \%)$, periódicos $(41,5 \%)$, y libros electrónicos en cuarto lugar. La radiografía se corresponde de manera bastante aproximada con el estudio sobre el consumo de contenidos digitales del Observatorio Nacional de las Telecomunicaciones y de la Sociedad de la Información (Ontsi, 2017).

Según la encuesta de Hábitos de lectura y compra de libros de la Federación Española de Gremios de Editores, el lector digital compra y lee más libros de media al año, posee una mayor cantidad de obras en su casa, y en general presen- ta parámetros de consumo que parecen sugerir un mayor compromiso con la lectura.

\section{El lector digital compra y lee más libros de media al año y posee una mayor can- tidad de obras en su casa}

Es difícil colegir de estos datos una influencia directa de un entorno determinado en los resultados de la lectura. Especular sobre lo puramente cuantitativo es complicado ante la falta de consenso de lo que es poco, mucho o suficiente. ¿Poseer 340 libros de media es un dato interpretable desde el punto de vista de la práctica lectora? Lo mismo ocurre con las compras o con la lectura en sí misma. Sabemos que, por un prurito de autoestima, se miente sobre los libros leídos cuando se responde una encuesta. Un estudio de la Reading Agency (2017) demostraba que el $41 \%$ de los encuestados mentía sobre su experiencia como lectores; en Francia, un elevado porcentaje de éstos reconocía que abandonaban 1 de cada 3 libros que había comenzado a leer o, como observábamos más arriba, el procedimiento de lectura se alimenta de numerosos saltos y elipsis. Es posible que ya se esté cumpliendo la implacable ley que formulara Stanislaw Lem:

"Nadie lee nada; si lee, no comprende nada; si comprende, lo olvida enseguida".

Bayard (2011) recomendaba procedimientos para hablar de los libros que no se han leído, y más recientemente Mikita Brottman (2018) desarrollaba un alegato contra la lectura, apelando a los lectores que no creen que los libros sean in- 

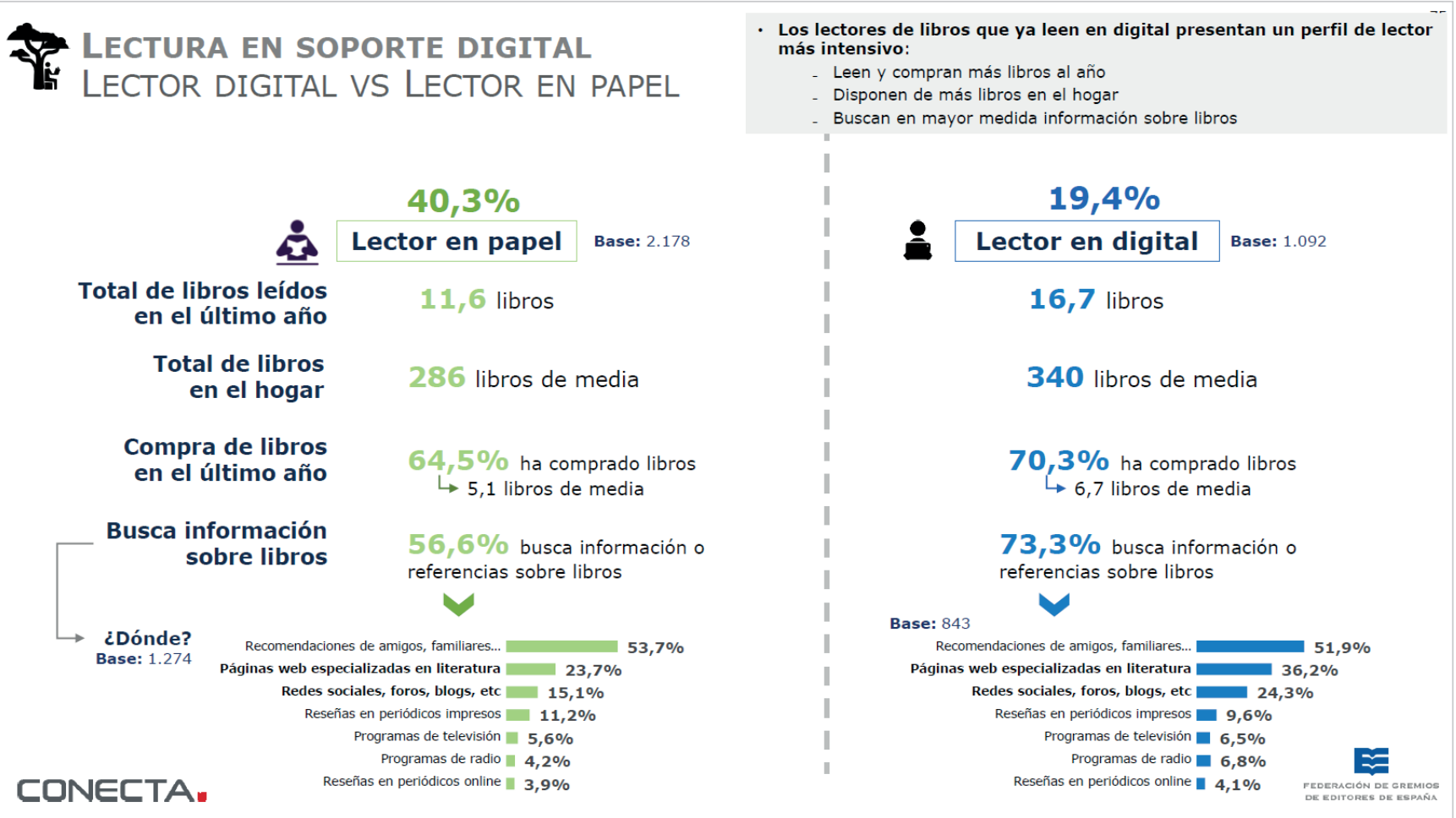

Figura 2. Lector papel vs. lector digital. Fuente: Hábitos de compra y de lectura de libros 2018.

tocables, aunque reivindicando en realidad la lectura y el lector exigentes que reclamaba Domingo-Argüelles (2017) o Schopenhauer que, en el segundo tomo de Parerga y $\mathrm{Pa}$ ralipómena, explicaba:

"el mucho leer quita al espíritu toda su elasticidad, como se la quita a un muelle un peso que lo presiona continuamente; y el medio más seguro para no tener pensamientos propios es echar mano de un libro cada vez que se tiene un minuto libre".

En uno de sus aforismos Lichtenberg decía que:

"hay muchísima gente que lee sólo para no tener que pensar",

sancionando aquella prédica de Nietzsche según la cual hay quien utiliza los libros como cerillas para poder encender el cerebro. Toda estadística sobre lectura adolece de esta tensión oculta entre realidad y representación que subyace en las industrias culturales. Quizá sería conveniente premiar la heterodoxia para aproximarnos a escenarios verosímiles sobre lectura, como ese concurso que se celebra entre académicos en el que se premia el reconocimiento de la no lectura de autores canónicos sobre los que habitualmente se pontifica en las clases. Aunque se trate de una de las irónicas ficciones de David Lodge (2006), pone el acento sobre la contextualización de las prácticas letradas. De cualquier modo, la lectura masiva de libros, como sostiene Carr (2017), ha sido una breve anomalía de nuestra historia intelectual. Es posible que estemos contemplando cómo ese tipo de lectura vuelve a su antigua base social: una minoría que se perpetúa a sí misma.

Independientemente de esto, las cifras abundan en una progresión de la lectura digital en todos los países de los que se tienen datos. Así se verifica en el estudio desarro-
Ilado por Two Sides (2017), en el que participaron 70,000 personas de Francia, Alemania, Italia, España, Reino Unido, Australia, Brasil, Nueva Zelanda, Sudáfrica y los Estados Unidos. En el mismo se constata la preferencia generalizada del papel sobre lo digital, por razones que se centran en la mayor capacidad de concentración, en la confiabilidad que otorga el soporte frente al fenómeno de las noticias falsas, en la fatiga digital, y en la confidencialidad. Pero se advierte una progresiva consolidación de la lectura, no tanto de libros como de otros media que van generando una lógica disruptiva frente a los medios tradicionales, constatable no sólo en la progresiva pérdida de peso del libro, sino también en el desplazamiento de uso desde dispositivos más tradicionales, como los ordenadores o los ereaders, hacia tablets y móviles, sobre todo estos últimos, que experimentan una progresión muy significativa como aparato de lectura y consumo de todo tipo de información.

\section{Un estudio de la Reading Agency (2017) demostraba que el $41 \%$ de los encues- tados mentía sobre su experiencia como lectores}

\section{Mixtificaciones y futuribles}

Estamos asistiendo a un desplazamiento desde una situación mimética de la producción digital (Cordón-García, 2016b; Sánchez-Muñoz, 2017), hacia contenidos y dispositivos que favorecen la intervención y participación proactiva gracias a una conectividad permanente y al desarrollo de software y aplicaciones, orientadas hacia ello. Incluso en los aparatos más tradicionales como los de tinta electrónica, se 
puede constatar cómo en 2017 y 2018 se ha consumado un cambio hacia la experimentación con pantallas de mayor tamaño, en un intento de concitar usos más orientados a la escritura que a la lectura, principalmente en el ámbito académico. En 2017 se lanzó el modelo Remarkable de 10 pulgadas después de generar más de 15 millones de dólares en pre-pedidos. Sony lanzó su segunda generación de papel digital, el DPT-RP1, un dispositivo de 13,3 pulgadas que está dirigido a los usuarios de empresa que trabajan con archivos PDF. Onyx también anunció tres nuevos e-readers de pantalla grande con una pantalla táctil Wacom y una capa para trabajar con lápiz stylus. Artatech ha lanzado InkBook Infinity con una pantalla Carta de 10,3 pulgadas, y una resolución de $1872 \times 1404$ y 267 ppi. En cuanto a los dispositivos, las innovaciones se centran en la conquista de espacios muy competidos, como el del entretenimiento, en el que la capacidad de expansión es limitada, dada la fuerte expansión de los años precedentes, por lo que su nicho de crecimiento vendrá por el lado profesional y académico. De ahí que los escasos movimientos operados en los dispositivos de tinta electrónica intenten avanzar por esa vía. También el mercado de las tablets se pronuncia por iniciativas similares. Los lanzamientos en 2018 de la Acer Chromebook Tab 10 y el nuevo modelo de iPad, así lo atestiguan. La primera permite colocar en red todos los dispositivos equipados con Chrome OS y la gestión de las licencias de Chrome Educación. Está equipada con un lápiz Wacom EMR para toma de notas y otras actividades, y cuenta con una resolución de $2048 \times 1536$ pixels en la pantalla. Por su parte Apple propuso en el mes de marzo de 2018 un nuevo iPad, orientado principalmente para alumnos y profesores. Cuenta con un procesador A10 Fusion, y la misma resolución que el Acer Chromebook. Está equipado con un lápiz óptico, hasta ahora reservado para los iPads de alta gama, compatible con casi todas las aplicaciones pedagógicas.

Los dispositivos y la lectura digital lejos de provocar la suplantación o desplazamiento del entorno impreso lo han reforzado

Los dispositivos y la lectura digital lejos de provocar la suplantación o desplazamiento del entorno impreso lo han reforzado. Se está produciendo una retroalimentación de dos sistemas que, gracias a la competencia por ocupar espacios en un contexto de economía de la atención tensionado por multitud de medios, han explorado sus rasgos diferenciales para someterlos a una optimización inexistente anteriormente. Esto se ha traducido en la introducción de elementos disruptivos en ambos entornos reforzando, en el caso de los impresos, los elementos de fisicidad más eficientes, esto es, aquellos que redundan en la visibilidad como objeto y en la legibilidad del contenido. La edición ha mejorado considerablemente su calidad, sobre todo en el caso de las numerosas editoriales independientes que han encontrado un nicho de mercado apostando por la singularidad de unas obras especialmente cuidadas por sus traducciones y su presentación, sometidas a una estricta selección, dirigidas a un público que valora la función editorial en aquellos aspec- tos que le confieren competencia técnica y excelencia profesional. Paradójicamente, ha sido el avance de la edición digital la que ha obligado al sector a moverse en el terreno de la calidad para competir en aquellos aspectos en los que el libro electrónico no puede entrar, descubriendo al paso características de lo físico que se habían olvidado por la inercia de la tradición (Mangen, 2016, 2017). Pero también el entorno impreso ha servido para subrayar aquellos rasgos más estrictamente vinculados con la lectura digital, como han puesto de manifiesto Roncevic (2017) y otros autores. Frente al mimetismo de períodos anteriores, se está avanzando en la convergencia de los libros electrónicos y la web, materializada recientemente por la fusión del World Wide Web Consortium (W3C) y el International Digital Publishing Forum (IDPF) abriendo nuevas posibilidades a la edición digital: curaduría de contenidos, actualizaciones permanentes, contenido dinámico, etc., de tal manera que los libros electrónicos estarán cada vez más vinculados a los lenguajes de marcado html y CSS. Más que nunca, el papel del editor se ve reforzado en la Web, que es a la vez un nuevo modo de publicación y difusión. Publicar en la Web significa agregar valor al contenido, satisfaciendo las exigencias de calidad con prácticas cada vez más complejas. El papel de las fuentes de pantalla, la calidad y la variedad de tipos de letra, colores o diseño, alimentan modelos editoriales cada vez más sofisticados, pero al mismo tiempo más flexibles para adaptarse a soportes o tiempos de lectura variables, reforzando una función editorial que parecía privativa y exclusiva del entorno impreso.

\section{Las cifras abundan en una progresión de} la lectura digital en todos los países

Estas tendencias se han materializado igualmente en sistemas preexistentes, que han encontrado en lo digital su nicho natural. Entre éstos destaca la autopublicación. Basada en la desregularización del sistema editorial, en la supresión de las intermediaciones, el fenómeno ha encontrado un particular encaje en las plataformas dedicadas a ello en la Red (Mangas-Vega, 2016). La proliferación de obras autopublicadas en todo el mundo, con cifras que se cuentan por cientos de miles de títulos, muestran una realidad disruptiva y novedosa, vinculada con el afán por escribir y dar visibilidad a lo escrito que, a tenor de las cifras y del crecimiento continuado de las mismas, constituye parte del adn comunicativo de la humanidad. El informe Bowker (2017), sobre el sector de la autopublicación en Estados Unidos, señala un incremento del 218,33\%, y tasas de crecimiento del 11\% entre los años 2011 y 2016. Por su parte Benchimol (2018) aporta para América Latina tasas de crecimiento del $400 \%$ durante los años 2007-2016. La fortaleza de las cifras indica que no se trata de un tendencia coyuntural, antes bien se ha ido consolidando con el tiempo, hasta el punto de que hay publicaciones especializadas y medios de comunicación que empiezan a incluir sus títulos en las listas de más vendidos o a elaborar reseñas de los mismos (Mangas-Vega; Gómez-Díaz; Cordón-García, 2016). Por otra parte, después de unos inicios de reserva y expectación, los editores han descubierto las posibilidades que ofrece este caladero para captar autores con proyección de mercado o para 
encajar manuscritos que no tienen cabida en su catálogo mediante acuerdos comerciales con plataformas de autopublicación. Aunque el fenómeno no es nuevo y habría que ubicarlo en el tradicional nicho de los "vanity publishers" (Cordón, 2016a), lo relevante es su reapropiación en el entorno digital dando salida al tumultuoso afán poligráfico de la sociedad. Si el canon es la excelencia, desde el punto de vista de la calidad y de las corrientes críticas dominantes en un momento dado, la autopublicación se ubica en las antípodas del mismo, excepto contadas excepciones. Carente de filtros, presidida por la necesidad de visibilidad y de circulación de escritos de toda naturaleza, intermediada editorialmente, cuando es el caso, en sus elementos puramente formales, mediante el pago de servicios, la autopublicación literaria constituye, en el mejor de los casos, el campo de pruebas para la experimentación y el placebo editorial, en el peor, el sumidero de la improvisación y el fracaso. Al no existir mecanismos legitimadores para la misma, y carecer de criterios discriminatorios que por otra parte, de haberlos constituirían un contrasentido con sus propósitos, la autopublicación se aproxima a una suerte de uberización de la escritura en la que el estatus del autor ha derivado en una figura más volátil, menos precisa y extremadamente frágil.

La autopublicación se aproxima a una suerte de uberización de la escritura en la que el estatus del autor ha derivado en una figura más volátil, menos precisa, y extremadamente frágil

Todo ello en un contexto de crisis de las mediaciones (Gauchet, 2009), en el que la hipertrofia generada por la oferta puede provocar el efecto inverso de retornar al lector hacia la seguridad de los editores legitimados por su tradición y catálogo. Si en el ámbito de la producción regulada, el de la edición convencional, se viene produciendo desde hace dos décadas un proceso de betselerización de la producción, con el predominio de criterios comerciales y de mercado (Schiffrin, 2011), fuera de sus límites el panorama es de un auténtico pandemónium alimentado por cientos de miles de autores en ciernes que, en palabras de Gabriel Zaid (2010), verán sus libros convertidos en

"una brizna del papel que se arremolina en las calles, que contamina las ciudades, que se acumula en los basureros del planeta".

En uno de los cuentos de Borges, Utopía de un hombre cansado, decía su protagonista que no importa leer, sino releer, que la imprenta había sido uno de los peores males del hombre por haber multiplicado hasta el vértigo los textos innecesarios, un vértigo que la autopublicación ha convertido en estructural. Hace unos años, Vila Matas daba noticia de la biblioteca de Burlington, creada en el Clark County Historical Museum de Vancouver, como homenaje a Richard Brautigan quien, en su novela El aborto, describía otra biblioteca, esta de ficción, cuyo cometido era recoger los manuscritos rechazados por las editoriales de todo el mundo. Hoy la realidad revierte al terreno de la ficción este centro, cuando la figura del autor inédito se ha convertido en historia y el "género" del rechazo, con inolvidables profesionales como Italo Calvino (1994), Roberto Calasso (2007), Roberto Bazlen (2012), Camilien Roy (2008), o Gabriel Ferraté (2012), es sólo una vía intermedia hacia otros derroteros.

\section{A modo de conclusión}

Después de todos estos estos años, la dicotomía impreso-digital ilustra un debate que no es nominalista sino cultural. Dos formas de cultura con modelos de referencia completamente diferenciados. La fascinación de lo impreso tiene que ver con su asentamiento durante siglos, pero también como horizonte de expectativas de una parte importante de la población para la que simboliza una aspiración relacionada con la realización personal, el prestigio, y con el magnetismo, en cierto modo fetichista, ejercido por un objeto, el libro, irreductible a explicaciones únicas. Lo ilustran bien algunos de los protagonistas del estudio etnográfico sobre la lectura coordinado por Francisco Cruces (2017) que, en unos casos, distraen dinero para comprar libros, y se deleitan en su contemplación cuando están ubicados en la biblioteca, y en otros, muestran el inefable placer de la percepción de los mismos como presencia permanente, aun sin mediar una voluntad de lectura decidida. Son testimonios que escapan de la anécdota para ilustrar la categoría de un modelo aún no definitivamente implantado en capas amplias de la población.

Como señala Greif (2018), la historia fundamental de la tecnología resulta ser en muchos casos la historia de la fantasía de sus usos. En el caso del libro nos encontramos ante un singular modelo de perfección, en su forma de códice impreso, un destilado de varios siglos de depuración y decante, del que se ha logrado eliminar toda suerte de escorias funcionales. No es extraño que Derrida hablara del "fin del libro y del comienzo de la escritura" refiriéndose a un sistema ya difícilmente superable más que en su textualidad, de la clausura de un período que se cierra al alcanzar su grado máximo de eficacia.

Pero en esta antinomia, que es la de la herramienta-máquina, aún nos encontramos en los estadios primigenios en los que la segunda no ha conseguido emular los niveles de simplicidad y usabilidad de la primera. La lectura digital se produce en un entorno poco amigable, a pesar de los avances en los dispositivos, en el que la carencia de interoperabilidad, la simultaneidad de formatos, la proliferación de plataformas, la indefinición de los modelos de negocio, la ineficiencia en los entornos de trabajo, impiden una superación razonable de los procesos inherentes a los sistemas impresos. La complejidad de los rudimentos asociados al diagrama de flujo digital, se inscribe en un panorama en que la estructura de todos los procesos sociales se va digitalizando pero en el que, paralelamente y en relación con la lectura, el referente impreso constituye un poderoso modelo imposible de desplazar. Al menos hasta que no se implemente toda una serie de variables vinculadas con la creación de sistemas amigables, ergonómicamente equiparables al impreso, funcionalmente superiores en eficiencia y usabilidad, e insertos en el circuito educativo con la misma naturalidad que lo digital se ha implantado en el flujo social. 
Los saltos tecnológicos en comunicación han experimentado siempre una fuerte resistencia. Curiosamente, Platón desautorizaba la escritura por desnaturalizar la memoria, y hoy se remite a la fisicidad para reclamar la misma. La separación del contacto directo con el objeto libro, o incluso con el papel, se ha percibido como pérdida cognitiva y social. La página nos permite, en algún momento del día, desconectar de la máquina y ocuparnos de nuestra esencia humana, sostiene Foer (2017). Cuando en 1881 Nietzche pierde su capacidad de escribir a mano y ha de recurrir a una máquina, comenta que "priva a la obra de su orgullo, de su bondad y de su humanidad". Sostenía en carta a un amigo que nuestras herramientas de escritura trabajan en nuestros pensamientos. Heiddeger, un poco más tarde, abundaba en la misma opinión, asegurando que ese aparato destruía con su clic mecánico la esencia misma del ser humano. No es extraño pues que cuando en Finlandia se anunciara el fin del aprendizaje de la escritura a mano, sustituida por la escritura mediante teclado, las reacciones fueran tan temperamentales.

A pesar de los avances en los dispositivos la lectura digital se produce en un entorno poco amigable

De cualquier modo, nuestras herramientas de escritura como anticipara Derrida y argumentara más recientemente Ferraris (2017), al transformarse, desencadenan movimientos intelectivos perceptibles tanto en la manera de percibir la realidad como de operar sobre ella. El libro electrónico es un paso más en esta evolución, cuya aparición sucede en momentos de perdida de centralidad del libro como herramienta de culturización y de reducción del tiempo recreativo, competido por ofertas culturales de otra naturaleza. Decía Manuel Cruz (2016) que hemos perdido "la experiencia de la duración, de la demora", y que ésta "ha sido sustituida por la sucesión ininterrumpida de intensidades puntuales". Los dispositivos tecnológicos favorecen la gestión de la espera, los distintos tipos de permanencia mediante la intervención en el tiempo en términos de una productividad que, singularmente, está relacionada con la escritura y la lectura (Ferraris, 2017; Wajcman, 2017; Köhler, 2018). Pero el tiempo del libro, impreso o electrónico remite a otra realidad no necesariamente relacionada con el rendimiento, la transparencia, o la productividad, remite a ese "punto de quietud en un mundo que gira" como señalaba Eliot en sus Cuartetos. Para poder pensar, mantiene Han (2016), hay que poder cerrar los ojos y contemplar, y para eso es necesaria una revolución que devuelva al tiempo su aroma. Quizá lo más disruptivo, en términos de libros electrónicos y lectura sea, parafraseando a Proust, buscar el tiempo perdido.

\section{Referencias}

Alonso-Burgos, Jesús (2017). Teoría e historia del hombre artificial. Barcelona: Akal. ISBN: 9788446044260

Domingo-Argüelles, Juan (2017). Qué leen los que no leen. México: Océano. ISBN: 9786075273310

Baron, Naomi (2016). Do students lose depth in digital read- ing?. The conversation.

https://theconversation.com/do-students-lose-depth-indigital-reading-61897

Bayard, Pierre (2011). Cómo hablar de los libros que no se han leído. Barcelona: Anagrama. ISBN: 9788433976512

Bazlen, Roberto (2012). Informes de lectura. Cartas a Montale. Buenos Aires: La bestia equilátera. ISBN: 978987 1739226

Benchimol, Daniel (2018). Radiografía de la autopublicación en América Latina. Bogotá: Colombia: Centro Regional para el Fomento del Libro en América Latina y el Caribe. https://goo.gl/HBjDBj

Boersenverein. GfK (2018). German ebook market 2017. https://goo.gl/hf5MFW

Bowker (2017). Self-publishing in the United States, 20112016: Print and ebook. Bowker.

https://goo.gl/sU63hP

Brottman, Mikita (2018). Contra la lectura. Blackie Books. ISBN: 9788417059545

Bruneau, Odette J. (2016). "Print vs. e-text: Student preferences in the digital age". Oneota reading journal. http://www.luther.edu/oneota-reading-journal/archive/2016/ digital-age

Calasso, Roberto (2007). Cien cartas a un desconocido. Barcelona: Anagrama. ISBN: 9788433962522

Calvino, Italo (1994). Los libros de los otros. Barcelona: Tusquets. ISBN: 9788472234123

Carr, Nicholas (2017). Superficiales: ¿Qué está haciendo Internet con nuestras mentes?. Madrid: Taurus. ISBN: 97884 30608126

Celaya, Javier (2018). "Presente y futuro del libro digital: la necesidad de nuevas estrategias editoriales". En: Bustamante, Enrique (coord.). Informe sobre el estado de la cultura en España igualdad y diversidad en la era digital. Madrid: Fundación Alternativas, pp. 159-170. ISBN: 9788415860662 https://goo.gl/XsGcFN

Childwise (2018). Monitor report 2017.

http://www.childwise.co.uk/reports.html\#monitorreport

Colletti, Marjan (2016). "Post-digital transdisciplinarity". Architectural design, v. 86, n. 5, pp. 74-81.

https://doi.org/10.1002/ad.2092

Cordón-García, José-Antonio (2016a). "La ruptura del campo editorial: la autopublicación y sus derivados". Anuario ThinkEPI, v. 10, pp. 278-283.

https://doi.org/10.3145/thinkepi.2016.61

Cordón-García, José-Antonio (2016b). "La lectura en el entorno digital: nuevas materialidades y prácticas discursivas". Revista chilena de literatura, n. 94, pp. 15-38.

https://revistaliteratura.uchile.cl/index.php/RCL/article/ view/44968/47050

Cordón-García, José-Antonio (2018). "Leer escuchando: reflexiones en torno a los audiolibros como sector emergente". Anuario ThinkEPI, v. 12, pp. 170-182. 
https://doi.org/10.3145/thinkepi.2018.23

Cordón-García, José-Antonio; Gómez-Díaz, Raquel; García-Rodríguez, Araceli (2016). "Operation patterns in recommendation systems: limitations, functionalities and performance in the digital environment". En: García-Peñalvo (ed.). Proceedings Teem'15: Third intl conf on technological ecosystem for enhancing multiculturality. Porto, Portugal, October 2014. ACM, 2016.

https://dl.acm.org/citation.cfm?id=2808580

Cramer, Florian (2015). "What is 'post-digital'?". En: Postdigital aesthetics: Art, computation and design, pp. 12-26. ISBN: 9781137437204

Cruces, Francisco (dir.) (2017) ¿Cómo leemos en la sociedad digital?: lectores, booktubers y prosumidores. Fundación Telefónica.

https://www.fundaciontelefonica.com/arte_cultura/ publicaciones-listado/pagina-item-publicaciones/itempubli/601

Cruz, Manuel (2016). Ser sin tiempo. Barcelona: Herder. ISBN: 9788425438615

Davies, Russell (2009). Meet the new schtick.

http://russelldavies.typepad.com/planning/2009/01/meetthe-new-schtick.html

Dosdoce; Bookwire. III Edition of the Spanish markets digital evolution report 2017.

http://www.dosdoce.com/wp-content/uploads/2017/05/ spanish-markets-digital-evolution-bookwire-dosdoce-2017.pdf

E-books market in Europe 2018-2022 (2018). Research and Markets.

https://www.researchandmarkets.com/reports/4450067/ebooks-market-in-europe-2018-2022

Encuesta de hábitos y prácticas culturales 2014-2015 (2016). Ministerio de Cultura.

https://www.mecd.gob.es/servicios-al-ciudadano/estadisticas/ cultura/mc/ehc/portada.html

Eisenstein, Elizabeth (1994). La revolución de la imprenta en la edad moderna europea. Barcelona: Akal. ISBN: 84 46002809

European book publishing statistics (2017). Federation of European Publishers.

https://goo.gl/8uzJYD

Ferraris, Maurizio (2017). Movilización total. Barcelona: Herder. ISBN: 9788425439247

Ferraté, Gabriel (2012). Noticias de libros (imprescindibles). Barcelona: Península. ISBN: 9788499421681

FGEE (2018). Habitos de lectura y compra de libros. Madrid, Federación de Gremios de Editores.

https://goo.gl/QdbZX1

Foer, Franklin (2017). Un mundo sin ideas. Barcelona: Paidós. ISBN: 9788449333699

Gauchet, Marcel (2009). "Les métiers du livre dans la crise des médiations". Les cahiers de la librairie, n. 7.

http://gauchet.blogspot.com.es/2009/07/les-metiers-dulivre-dans-la-crise-des.html
Greif, Mark (2018). Contra todo: como vivir en tiempos deshonestos. Barcelona: Anagrama. ISBN: 9788433964182

Han, Byung-Chul (2016). Por favor, cierra los ojos: a la búsqueda de otro tiempo diferente. Barcelona: Herder. ISBN: 9788425436321

Intellectual Property Office (2017). Online Copyright infringement tracker: Latest wave of research.

https://assets.publishing.service.gov.uk/government/ uploads/system/uploads/attachment_data/file/628704/ OCl_tracker-7th-wave.pdf

Kaufman, Geoff; Flanagan, Mary (2016). "High-low split: Divergent cognitive construal levels triggered by digital and non-digital platforms". In: Proceedings of the $2016 \mathrm{CHI}$ Conference on human factors in computing systems (CHI '16). ACM, New York, pp. 2773-2777.

https://doi.org/10.1145/2858036.2858550

Köhler, Andrea (2018). El tiempo regalado. Madrid: Libros del Asteroide. ISBN: 9788417007331

Library journal (2018). Academic student ebook experience survey.

https://lj.libraryjournal.com/downloads/2018-academicstudent-ebook-experience-survey-report

Lluch, Gemma (2017). “Los jóvenes y los adolescentes comparten la lectura”. En: Francisco Cruces (dir.) ¿Cómo leemos en la sociedad digital?: lectores, booktubers y prosumidores. Fundación Telefónica, pp. 30-51.

https://www.fundaciontelefonica.com/arte_cultura/ publicaciones-listado/pagina-item-publicaciones/itempubli/601

Lodge, David (2006). Intercambios. Barcelona: Anagrama. ISBN: 9788433967404

Mangas-Vega, Almudena (2016). Autopublicar: los nuevos circuitos para autores e investigadores. Colección EPI-UOC. Barcelona: UOC. ISBN: 9788491165866

Mangas-Vega, Almudena; Raquel Gómez-Díaz; José-Antonio Cordón-García (2016). "Approach to self-publishing with a combination of bibliometric study and social network analysis techniques". The electronic library, v. 34, n. 6, pp. 902-914. https://doi.org/10.1108/EL-02-2016-0030

Mangen, Anne; Van-der-Weel, Adriaan (2016). "The evolution of reading in the age of digitisation: an integrative framework for reading research". Literacy, v. 50, n. 3, pp. 116-124.

https://onlinelibrary.wiley.com/doi/full/10.1111/lit.12086

Mangen, Anne; Van-der-Weel, Adriaan (2017). "Why don't we read hypertext novels?". Convergence: The international journal of research into new media technologies, v. 23, n. 2, pp. 166-181.

https://doi.org/10.1177/1354856515586042

Merga, Margaret K.; Roni, Saiyidi-Mat (2017). "The influence of access to ereaders, computers and mobile phones on children's book reading frequency". Computers and education, v. 109, n. C, pp. 187-196.

https://doi.org/10.1016/j.compedu.2017.02.016

Meyer, Kate (2016). Reading content on mobile devices. 
Nielsen Norman Group.

https://www.nngroup.com/articles/mobile-content

Millán, José-Antonio (coord.) (2002, 2008, 2017). La lectura en España: Informe. Federación de Gremios de Editores. http://www.fge.es/lalectura/2017/default.html

Milliot, Jim (2016). As e-book sales decline, digital fatigue grows. Publishers Wekly.

https://goo.gl/vrDAhe

Myrberg, Caroline (2017). "Why doesn't everyone love reading e-books?". Insights, v. 30, n. 3, pp. 115-125.

http://doi.org/10.1629/uksg.386

MUSO (2018). Annual piracy reports 2017.

https://www.muso.com/annual-piracy-reports

Negroponte, Nicholas (1998). "Beyond digital". Wired, January 12 th.

https://www.wired.com/1998/12/negroponte-55

Observatoire de l'économie du livre (2018). Le secteur du livre: chiffres-clés 2016-2017.

https://goo.gl/cgkyMH

Observatorio de piratería y hábitos de consumo de contenidos digitales 2017 (2018). Coalición de creadores industrias de contenidos. GfK.

http://lacoalicion.es/wp-content/uploads/ejecutivo-es.pdf

Observatorio del libro y de la lectura. El sector del libro en España: 2017.

https://goo.gl/7SBSZ6

Ontsi (2017). Estudio de uso y actitudes de consumo de contenidos digitales. Observatorio Nacional de las Telecomunicaciones y de la SI.

http://www.ontsi.red.es/ontsi/es/content/estudio-de-uso$y$-actitudes-de-consumo-de-contenidos-digitales

Paganelli, Céline; Chaudiron, Stéphane; Zreik, Khaldoun (dir.) (2017). "Documents et dispositfs à l'ère post-numérique". In: CIDE 18. Actes du 18e Colloque international sur le document electrónique. Europia.

http://europia.org/edition/livres/doc/Cide18.htm

Panorámica de la edición española de libros 2016 (2017). Madrid: Ministerio de Educación, Cultura y Deporte. https://www.mecd.gob.es/cultura/areas/libro/mc/pee/ contenedora/presentacion.html

Perbal, Bernard (2017). "Neuroscience and psychological studies sustain the cognitive benefits of print reading". Journal of cell communication and signaling, v. 11, n. 1 , pp. 1-4.

https://doi.org/10.1007/s12079-017-0379-5

Reading Agency (2017). Talking fiction? Research reveals our reading habits and hang-ups.

https://goo.gl/fvCogP

Reading the reader: A survey of Australian reading habits
(2017). Macquarie University; Australia Council for the Arts. http://www.australiacouncil.gov.au/workspace/uploads/ files/readers_survey_summary_final_v-592cf39be2c34.pdf

Reimers, Imke (2016). "Can private copyright protection be effective? Evidence from book publishing". The journal of law and economics, v. 59, n. 2, pp. 411-440.

https://doi.org/10.1086/687521

Roncevic, Mirela (2017). Defending the honor of ebooks (and innovation). No shelf required.

http://www.noshelfrequired.com/defending-the-honor-ofebooks-and-innovation

Roy, Camilien (2008). El arte de rechazar una novela. Barcelona: Bruguera. ISBN: 9788402420992

Sánchez-Muñoz, Elena (2017). "La lectura digital: perspectiva transhistórica y cognitiva". Métodos de información, v. 8, n. 14. http://www.metodosdeinformacion.es/mei/index.php/mei/ article/view/IIMEl8-N14-067088

Schiffrin, André (2011). El dinero y las palabras. La edición sin editores. Barcelona: Península. ISBN: 9788483078648

Singer, Lauren M.; Alexander, Patricia A. (2017). "Reading on paper and digitally: What the past decades of empirical research reveal". Review of educational research, v. 87, n. 6, pp. 1007-1041.

https://doi.org/10.3102/0034654317722961

Taffel, Sy (2015). Perspectives on the postdigital: Beyond rhetorics of progress and novelty. Convergence, v. 22, n. 3 , pp. 324-338.

https://doi.org/10.1177/1354856514567827

Two Sides (2017). Print and paper in a digital world - An international survey of consumer preferences, attitudes and trust. https://goo.gl/EjM8vm

Topping, Keith (2017). What kids are reading report. Renaissance.

http://whatkidsarereading.co.uk/download/download-thefull-report

Wajcman, Judy (2017). Esclavos del tiempo. Barcelona: Paidós. ISBN: 9788449333149

Wetzig, Dennis (2012). Are we in the post-digital era? No way! http://www.dennis-wetzig.com/2012/05/are-we-in-thepost-digital-era-no-way

Wischenbar, Rüdiger (2017). Global ebook report: As many stories as markets.

https://publishingperspectives.com/2017/05/global-ebookreport-2017-many-markets

Zaid, Gabriel (2010). Los demasiados libros. Barcelona: Debolsillo. ISBN: 9788499082240

Zielinski, Siegfried (2015). After the media: News from the slow-fading twentieth century. Univocal Publishing. ISBN: 9781937561161 


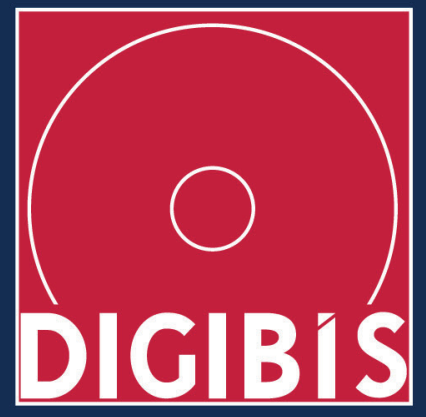

Nuestra vocación: contribuir a que el patrimonio cultural español sea preservado digitalmente y se difunda de la manera más amplia posible

Con metadatos ajustados a la normativa internacional

Aplicaciones Linked Open Data (LOD) con Reconciliación Semántica

Aplicaciones que pueden incorporar Recolector y Repositorio OAI-PMH

Aplicaciones pensadas y desarrolladas para hacer más eficiente y ágil el trabajo de los administradores y más comprensible para el usuario el acceso a los recursos catalogados. 